\title{
Gracq et la modernité fragmentaire
}

\section{François Demont}

\section{OpenEdition}

Journals

Édition électronique

URL : http://journals.openedition.org/edl/2401

DOI : 10.4000/edl.2401

ISSN : 2296-5084

\section{Éditeur}

Université de Lausanne

\section{Édition imprimée}

Date de publication : 15 mars 2020

Pagination : 147-150

ISBN : 978-2-940331-73-4

ISSN : 0014-2026

\section{Référence électronique}

François Demont, «Gracq et la modernité fragmentaire », Études de lettres [En ligne], 312 | 2020, mis en ligne le 24 mars 2020, consulté le 10 décembre 2020. URL : http://journals.openedition.org/edl/ 2401 ; DOl : https://doi.org/10.4000/edl.2401

(c) Études de lettres 


\section{GRACQ ET LA MODERNITÉ FRAGMENTAIRE}

Alors que le mois de décembre 1980 s'achève, Philippe Muray écrit dans son journal qu' "une nouvelle préhistoire" s'entame ${ }^{1}$. La même année, Julien Gracq avait souligné la rapidité avec laquelle «les époques se succèdent et se remplacent ${ }^{2}$. Dans ce temps fragmenté, 1980 est souvent considérée comme une balise marquant le seuil d'une certaine modernité littéraire - même si ce concept est un "fourre-tout critique» ${ }^{3}$.

Pourtant, pour qui tente d'échapper à la projection rétrospective en ne privilégiant pas "au détriment des ouvres de transition et des œuvres inconsciemment grosses de l'avenir - toutes les formes clairement agressives de la rupture» (p. 246), l'an 1980 paraît agité par des courants contraires. Qu'importe l'étiquette, il est alors commun de penser qu' «être moderne, c'est bricoler dans l'Incurable» ${ }^{4}$ et que la modernité «érode les savoirs d'époque, défait le confort formel et propose moins de sens qu'une inquiétude sur les conditions de production d'un sens communément partageable » ${ }^{5}$. Rien ne paraît ainsi plus littéraire que d'écrire sur l'échec et l'impossibilité de l'écriture littéraire.

"On ne rêve [alors] que morcellement. " ${ }^{6}$ Or l'écriture dite «fragmentaire» est emblématique de cette situation où tout semble être de

I. Ph. Muray, Ultima necat I, p. 110.

2. J. Gracq, En lisant en écrivant, p. 191; les pages indiquées entre parenthèses renvoient à cet ouvrage.

3. P. Berthier, M. Jarrety (éds), Histoire de la France littéraire, Modernités XIX $X^{e}$ $X X^{e}$ siècles, p. 432.

4. E. Cioran, Syllogismes de l'amertume, p. 180.

5. Ch. Prigent, À quoi bon encore des poètes?, p. 10.

6. J.-P. Aron, Les modernes, p. 301. 
trop et venir trop tard; où la littérature se fait épilogue, faute de mieux. Cioran le résume: «Faute de savoir vers quoi se diriger, affectionner la pensée discontinue, reflet d'un temps volé en éclats. " ${ }^{7}$ Aucune inflexion majeure ne s'est produite en 1980, mais on peut évoquer le surgissement - ou l'accentuation - d'un discours sur le fragmentaire comme étant caractéristique de ce moment de la modernité.

À la fois élan et résistance, le discours fragmentaire préexiste à 1980. Pourtant, l'idée d'une écriture confinée au fragment et renvoyée par là-même à sa propre impossibilité ou à sa superficialité semble caractéristique de la modernité. Il est ainsi loisible de penser l'écriture fragmentaire autour de 1980 sur le mode de la coda ou sur celui de la tabula rasa. Mais ces points de vue se complètent - le regard de l'observateur dessinant seul ou presque les dynamiques de l'histoire littéraire. Barthes publie Fragments d'un discours amoureux en 1977, Cioran Écartèlement en 1979, Blanchot L'écriture du désastre en 1980 et Quignard achève ses Petits traités la même année. Si chacun de ces livres est différent, leur mode d'énonciation est similaire - et témoigne, peut-être, d'un même imaginaire du présent de la littérature. De fait, si une idée ressort des poétiques du fragment, c'est bien ainsi celle d'une négativité, d'une impossibilité de la représentation par l'écriture, de même qu'une remise en cause radicale d'une littérature totale et harmonieuse. Sans jamais parvenir à être vraiment présente à elle-même, l'écriture fragmentaire, malgré sa déréliction, reste hantée par le "démon de la totalité", selon l'expression de Claude Coste. Le fragment pourrait ainsi sembler aller de pair avec une sorte d'amour de la littérature déçu, qui dirait son échec en s'énonçant. Consistant à "écrire par défaut", le fragmentaire donc "promet le désarroi, le désarrangement" ${ }^{8}$.

C'est en 1980 que Julien Gracq publie En lisant en écrivant - essai plus fragmenté que fragmentaire. Il soutient qu'en cette fin de $\mathrm{XX}^{\mathrm{e}}$ siècle, on se nourrit «chez les grands écrivains du passé, de ce qu'ils auraient regardé comme les miettes de leur table» (p. 251). Aux grands romans, le goût du temps préfère les journaux, les carnets, les brouillons ou encore les entretiens, "comme si la masse d'une œuvre consacrée [...] servait surtout aujourd'hui de laisser-passer pour l'indiscrétion, pour le tout-venant, le primesaut du premier jet» (p. 252 sq.). Or Gracq, qui a lui-même puisé

7. E. Cioran, Aveux et anathèmes, p. 1120.

8. M. Blanchot, L'écriture du désastre, p. 17 et 22. 
dans ses cahiers pour rédiger son essai, précise que l'époque veut de "la littérature qui bouge et saisie dans le moment même où elle semble bouger encore»; et de résumer en une belle formule: «ce que nous ne voulons plus, c'est la littérature-monument» (p. 252). Le fragment chez Gracq découle d'ailleurs d'une écriture insulaire, ou plutôt de la presqu'île, tout en liens, en ouvertures et en échos. Elle participe de ce goût pour le document qui caractérise notamment la modernité; et Gracq confie:

Ce que j'écris ici ne doit être pris à aucun titre pour un désaveu de mon époque: je penche moi aussi [...] du côté où elle penche. (p. 252)

On pourrait penser que l'écriture fragmentaire d'En lisant en écrivant surgit elle aussi des failles de la littérature. Il n'en est rien. À l'instar de Barthes dans Le plaisir du texte (1973), Gracq consacre une majeure partie de son volume à la jouissance sensuelle - et quasi érotique - qu'offre la littérature, où la lecture mène à l'écriture: "on écrit d'abord parce que d'autres avant vous ont écrit» (p. 131). À la suite de Valéry - ce «gymnasiarque qui critiquerait le manque d'économie des mouvements du coït» (p. 103) à qui il s'oppose souvent et qu'il tutoie (p. 146) - Gracq veut voir «comment c'est fait» (p. 43). Un réseau métaphorique liant la littérature à la joie sensorielle et gustative émaille ainsi son texte de manière continue. S'il y a chez Stendhal « je ne sais quel oxygène qui donne au style son pétillement et son champagne", l'épisode de Waterloo dans La chartreuse de Parme est un «hors-d'œuvre» (p. 47), «apéritif et gastronomique» (p. 65).

C'est qu'«en tout objet qui agit par la séduction, le charme, le seul vrai charme est épidermique» (p. 69). Gracq soutient ainsi que la «coulée verbale» (p. 69) de Balzac est «nourrissante et poisseuse comme une confiture" (p. 96), quand la prose de Proust est "surnourrie», tandis que la lecture de Guerre et Paix se rapproche d'une "manducation comblante et nourrissante» (p. 115) ou encore que la relation de l'écrivain à la langue est similaire à celle "qu'on a avec une servante-maîtresse" (p. 131). Quant à l'œuvre de Goethe, Gracq souligne avec humour «son arrière-goût de veau froid mayonnaise" (p. 205). Si, pour lui, le vers de Baudelaire est "lourd de cette pesanteur spécifique du fruit mûr» (p. 140), l'écrivain a, de manière générale, un "goût quasi charnel [...] pour les mots", et Gracq lui-même confie être sensible à la "succulence" $\mathrm{du}$ «mot-nourriture» (p. 142). Loin du pessimisme linguistique dont le $\mathrm{XX}^{\mathrm{e}}$ siècle fut généralement empreint, Gracq écrit d'ailleurs qu'il n'est d'autre moyen de communication que «la langue qui [lui] est donnée» et 
déclare: «je fais avec ce que j’ai» (p. 228). Le rôle dévolu au critique, cet " expert en objets aimés", par Gracq semble du reste clair: il a pour tâche de lui dire d'où vient dans une lecture le "plaisir qui ne se prête à aucune substitution" (p. 160). Ainsi, même lorsque Gracq se ravit du caractère si «exquisément faisandé» du vocabulaire de Huysmans, il est toujours à la recherche d' "une sorte de pourlèchement linguistique" (p. 188 sq.).

Moderne non dupe de lui-même, Gracq a donc le fragment heureux et l'écriture nourrie, confortée et assurée par ses lectures. Alors que Sartre, Gary et Barthes meurent en 1980 et que Tel Quel cesse de paraître en 1982, En lisant en écrivant atteste que la littérature est toujours bien vivante et pleine d'allant - l'engouement négatif et le formalisme des années précédentes s'étant peu à peu épuisé. Le goût pour le roman et le plaisir de la narration ressurgissent. Par l'assemblage a priori oxymorique d'une forme fragmentaire et d'une foi déclarée en la littérature, En lisant en écrivant révèle ainsi, en dépit de son caractère réflexif, plusieurs lignes de force des années 1980 - période résolument plurielle et transitoire.

François Demont

Section de français, Faculté des lettres, Université de Lausanne

\section{BIBLIOGRAPHIE}

Aron, Jean-Paul, Les modernes, Paris, Gallimard, 1984.

Berthier, Patrick, Jarrety, Michel (éds), Histoire de la France littéraire, Modernités XIX ${ }^{e}-X X^{e}$ siècles, Paris, PUF, 2015.

Blanchot, Maurice, L'écriture du désastre, Paris, Gallimard, 1980.

Cioran, Emil, Syllogismes de l'amertume et Aveux et anathèmes, in Euvres, Paris, Gallimard, 2011.

Coste, Claude, «Roland Barthes par Roland Barthes ou Le démon de la totalité», Recherches \& Travaux, 75 (2009), p. 35-54.

GracQ, Julien, En lisant en écrivant, Paris, Corti, 1980.

Muray, Philippe, Ultima necat I, Journal intime 1978-1985, Paris, Les Belles Lettres, 2015.

Prigent, Christian, À quoi bon encore des poètes?, Paris, P.O.L, 1996. 